\title{
DESIGN, MANUFACTURING AND TESTING OF A ROTORCRAFT ACCESS PANEL DOOR FROM RECYCLED CARBON FIBER REINFORCED POLYPHENYLENESULFIDE
}

\author{
T.A. de Bruijn ${ }^{1,2 *}$, G.A. Vincent ${ }^{3}$, J. Meuzelaar ${ }^{4}$, J.P. Nunes ${ }^{2}$, F.W.J. van Hattum ${ }^{1}$ \\ ${ }^{1}$ ThermoPlastic composites Application Center, Saxion University of Applied Sciences \\ Ariensplein 1, $7511 \mathrm{JX}$ Enschede, The Netherlands \\ *Corresponding author: t.a.debruijn@ saxion.nl, +31638302033 \\ ${ }^{2}$ Institute for Polymers and Composites, University of Minho \\ Campus de Azurem 4800-058 Guimarães, Portugal \\ ${ }^{3}$ ThermoPlastic composites Research Center \\ Palatijn 15, 7521 PN Enschede, The Netherlands \\ ${ }^{4}$ GKN Fokker \\ Industrieweg 4, 3351 LB Papendrecht, The Netherlands
}

\begin{abstract}
An integrally-stiffened access panel for a rotorcraft is selected for detail design, testing and actual flight to demonstrate a novel recycling route for thermoplastic composites. The design, development and validation followed the 'Building Block approach'. The used material is postindustrial carbon fiber reinforced polyphenylene sulfide waste. This material originates from thermoplastic components of the very same rotorcraft as the panel will be mounted on, improving traceability, logistics and fixing supply and demand. Material data have been gathered from mechanical tests and used to predict the panels strength and stiffness. A critical design detail was selected and tested for validation. This section was included in a manufacturing demo, along with other integrated design features, enabling testing the processability. The final panel design was successfully produced and tested on component level. The re-manufacturing process includes simultaneously applied heat and low-shear mixing, followed by compression molding in an isothermal mold. This offers the possibility to retain long fibers and therefore high mechanical properties at short cycle times. In comparison to the current carbon/epoxy solution, the resulting product is lighter, significantly more cost-effective and made of recycled material (fiber and matrix). The prototype panel is targeted for flight testing on the rotorcraft in 2019.
\end{abstract}

Copyright 2019 by T.A. de Bruijn. Used by the Society of the Advancement of Material and Process Engineering with permission. SAMPE Conference Proceedings. Charlotte, NC, May 20-23, 2019. Society for the Advancement of Material and Process Engineering - North America. 


\section{INTRODUCTION}

\subsection{Recycling thermoplastic composites}

The volume of continuous fiber reinforced thermoplastic composites (TPCs) is increasing in aerospace (and other industries) because of material benefits including cost-effective manufacturing and fast processing. This material also enables unique thermal processing techniques such as welding and is known for a high impact resistance and recyclability [1]. TPC recycling offers many advantages due to the high economical value of the material, the high environmental impact of carbon fiber and the more stringent environmental directives and regulations [2]. In the current study, the TPC-Cycle recycling route previously developed to process TPCs at low economic and environmental cost, while retaining high mechanical properties is used $[3,4]$. This process is roughly based on well-known GMT/LFT-processing, widely used in e.g. the automotive industry. It thus provides a robust and cost-effective novel processing route for the aerospace industry, including relevant design guidelines [5]. As shown in Figure 1, the recycling route consist of several steps. Post-industrial waste is collected and shredded to flakes with a long fiber length [6]. The material is heated and mixed in a low-shear mixer and compression molded to a part. This solution offers the possibility to process long fiber lengths, known to exhibit high modulus, strength and impact properties as visualized in Figure 2. The solution differs from TPC recycling approaches that use the material as a bulk molding compound in a non-mixing process $[7,8]$. A mixing solution is preferred for multiple reasons:

- Increasing the reinforcement aspect ratio, disentangling flakes to fiber bundles and therefore improving the mechanical performance of the material.

- No need for a full consolidation cycle resulting in a significant reduction of processing times

- Offering the opportunity to use thick consolidated waste material

- Offering a cost-effective solution, contrary to the large investments of the industrially applied Direct LFT, but with a similar approach process-wise.

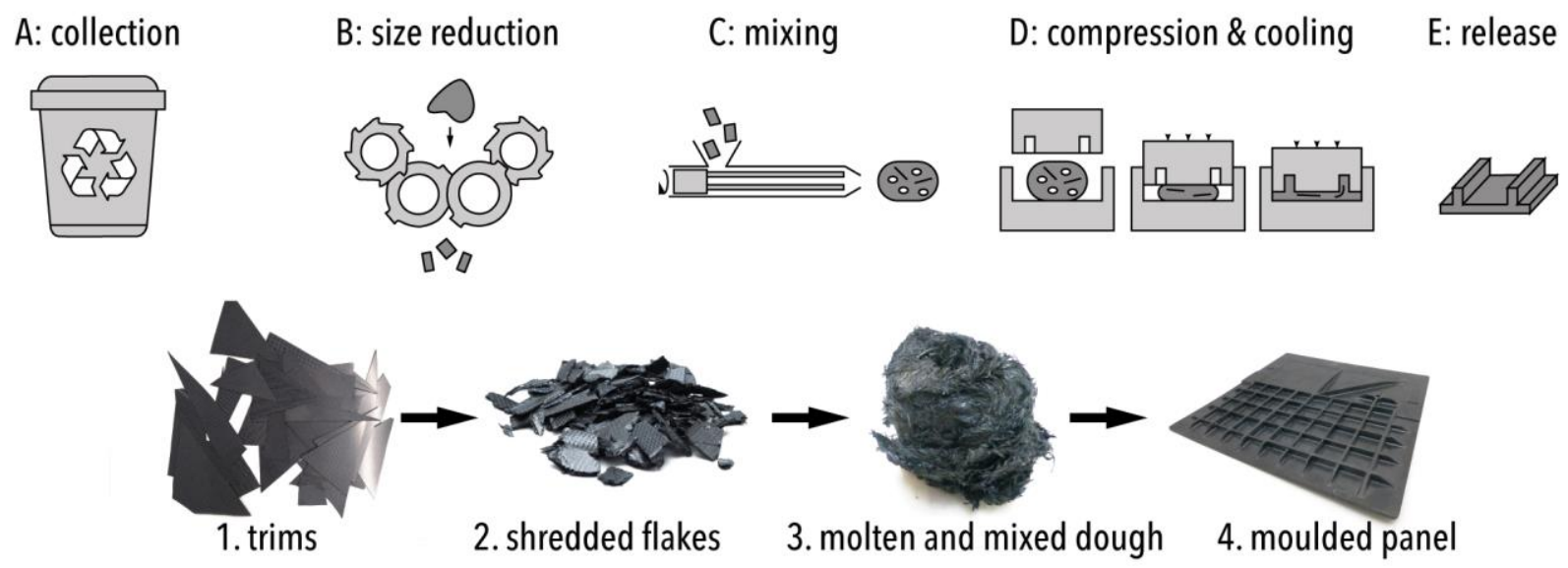

Figure 1. TPC-Cycle recycling route 


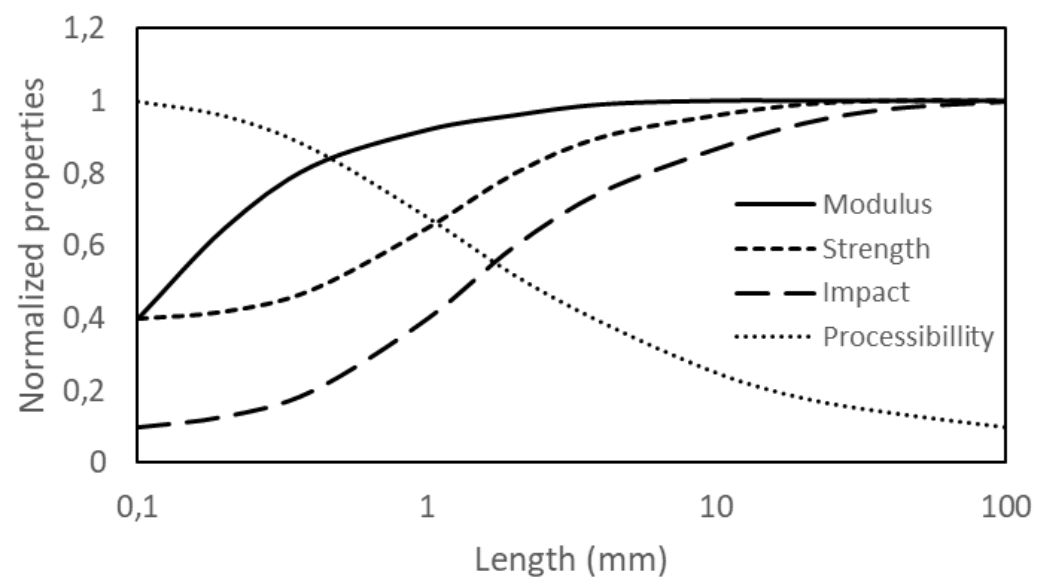

Figure 2. Influence of fiber length on normalized mechanical properties [9,10]

\subsection{Rotorcraft access panel}

The developed access panel is a part for a new developed rotorcraft. The goal of this rotorcraft is to offer increased performance (speed, range, payload and agility) at affordable cost. To achieve these goals, composites are used throughout the structure (low weight, fatigue \& corrosion insensitive). The access panels are created from the actual production waste of TPC components intended for the same rotorcraft structure (i.e. closed-loop recycling). The requirements for the access panels are fully representative for any aerospace part; including sufficient strength at ultimate load (UL), prescribed maximum deflection at limit load (LL) (to guarantee aerodynamic performance), chemically and thermally resistant. The panel must fit the design space and needs to be interchangeable with the current panel made of thermosetting carbon epoxy prepreg composite by hand layup. The access panel is a rectangular non-structural component, with a prescribed thickness at the landing and is mounted by fasteners. The specific design goal is to minimize weight and cost of the panel.

The overall goal of this study is to design, manufacture, test and fly an aerospace part of recycled TPC material to show the technical and economic feasibility of the developed recycling solution.

\subsection{Development Approach}

The traditional 'Building Block approach' (as advocated in [11]) is chosen for the design and validation of this novel composite material and process, see Figure 3. Mechanical properties of the material were used on coupon level (samples from flat plates of various fiber volume fractions) and the results were used for the design. From FEM optimizations on the design, the most critical design detail was selected and tested. A series of panels was produced of which one representative panel was selected for the component test and two panels were selected for actual flight. The results are presented and discussed before the conclusion is given. 


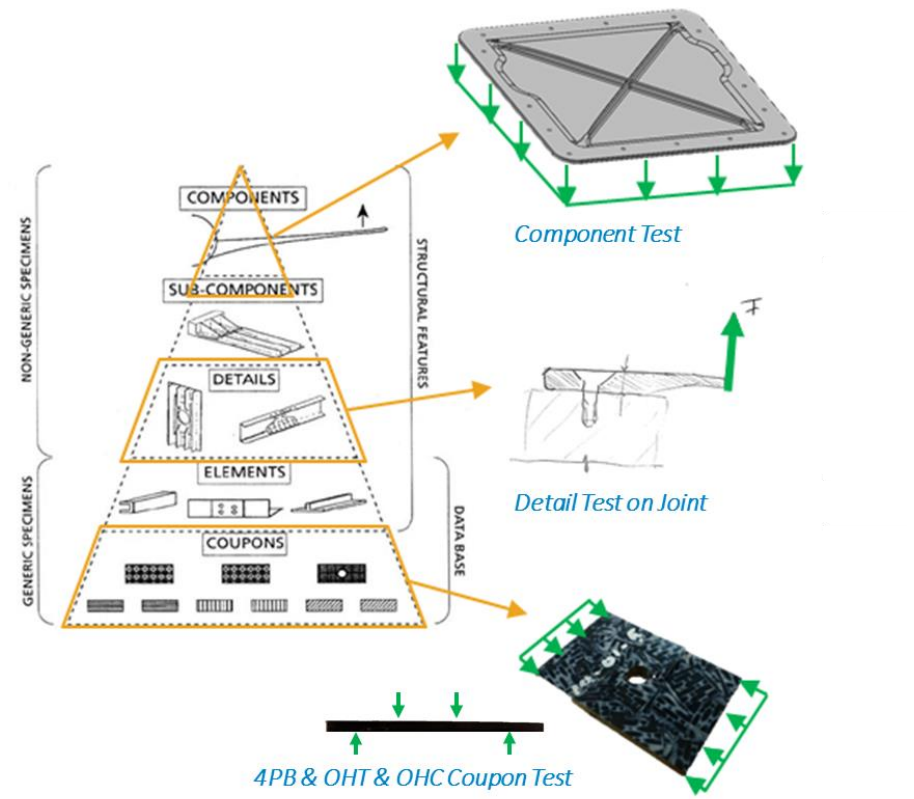

Figure 3. Building Block test approach as followed for the recycled access panel, source: adapted from [11]

\section{DESIGN}

\subsection{Finite element model}

FEM models for design iterations were made using the SolidWorks software package, which was chosen for its wide availability and ease-of-use, which significantly speeds up to the initial design iterations. The final design was validated by a set of Patran/Nastran simulations. The prescribed aerodynamic pressures have been applied uniformly over the panel at LL and UL levels to verify stiffness and strength requirements, respectively.

\subsection{Design}

The design was optimized for weight by reducing the thickness of the panel to the minimum producible thickness of $2 \mathrm{~mm}$ and scaling the ribs to obtain the required stiffness. Multiple concepts with different rib design were evaluated and compared. Two diagonal crossing ribs were chosen to lead the stress towards the corners in order to distribute the stresses more equally over the fixation points. The edge of the panel was fixed on the prescribed interface thickness to comply with adjacent parts. The design was evaluated using FEM for deflection and stress level. The maximum stress is localized around the fastener holes as shown in Figure 4, a situation where the FEM model might not give a realistic result because it is very sensitive to the chosen boundary conditions. Besides the fastener locations, high stresses were found at the stiffener crossing. Moreover, the local loading situation is complex: combination of laminate bending, fastener bearing and pull-through. Therefore experimental detail tests were performed to test the complex loading situation. 

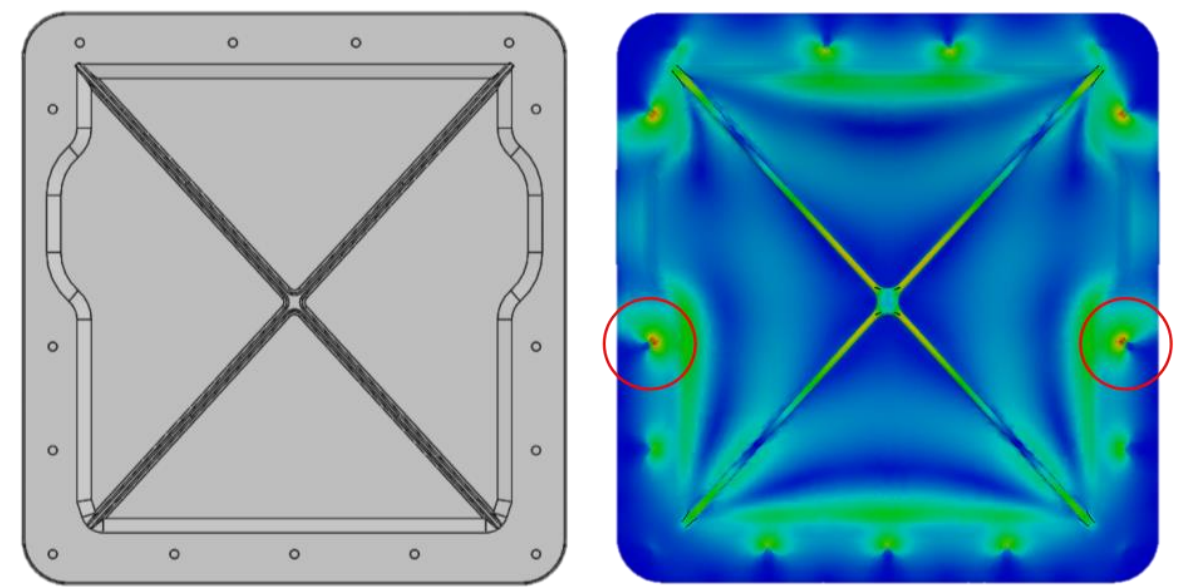

Figure 4. The CAD model (left) and stress distribution (right) of the final concept, red circles indicate stress concentration at fasteners

The final design results in a weight reduction of $9 \%$ with respect to the current baseline C/epoxy prepreg design. The deformation at LL is predicted to be within the stiffness requirements. Regarding strength, the stresses in the ribs are at an acceptable level, even compared to a conservative preliminary tensile strength value which has been statistically reduced for variation (B-value) and elevated temperature. The stress concentration at the fasteners is still above this value for plain tension, but has been validated by the detail tests.

\section{MATERIALS AND METHODS}

\subsection{Materials}

The used material is post-industrial C/PPS waste. This material originates from the same structure as the access panel will be mounted on. The batch number and history of the material is therefore known, and enables the required traceability. Since the material is recycled near the production facility, the logistics are less complicated and prevent unnecessary environmental impact. This solution additionally implies a fixed supply and demand resulting in a lower risk from a business point of view.

Offcuts from a consolidated C/PPS laminate (TenCate Cetex ${ }^{\circledR}$ TC1100), consisting of multiple plies of 5 harness satin weave, are fed into an Untha S20 shredder for five consecutive times. The output of this low-speed two-shaft shredder with blades of $19 \mathrm{~mm}$ in width and no screen were long fiber length of 15 to $20 \mathrm{~mm}$ [6]. In this case, the offcuts were nesting residues of the ribs made by GKN Fokker. Flake sizes are automatically analyzed and translated to a fiber length distribution by an in-house developed image processing tool. More information about the used shredding method and fiber length analysis is available in a study by Vincent et. al. [6]. The material is diluted with Celanese Fortron 0214 PPS pellets (i.e. identical matrix as the recycled $\mathrm{C} / \mathrm{PPS}$ laminate) to lower the fiber volume content $\left(\mathrm{V}_{\mathrm{f}}\right)$ to $20 \%$. Material data were gathered in a previous study from mechanical tests and used to predict the panels strength and stiffness, see Table 1 [4]. These properties were found to be much less orientation dependent than injectionmolded materials. Local variations (fiber volume fraction/fiber alignment) are expected to give some scatter in strength, but not in global stiffness of the laminate. 
From the bending tests, it can be concluded that stiffness of the recycled material processed by low shear mixing is reduced to roughly one-third of the baseline C/PPS material (quasi-isotropic laminate) due to the shorter fiber length and strongly reduced fiber volume fraction (20\% versus $51 \%)$. For non-structural applications like this access panel, this is actually considered a benefit since a lower in-plane stiffness will prevent undesired load transfer into the panel; on the other side the out-of-plane stiffness can be tailored to the required value by means of integral stiffening offered by this technology.

Table 1. Preliminary material properties deducted from 4-pnt bending test (all values Room Temp/average)

\begin{tabular}{|l|c|}
\hline Material properties & Recycled C/PPS at 20\% V \\
\hline Density $\left[\mathrm{kg} / \mathrm{m}^{3}\right]$ & 1460 \\
\hline Flexural strength $[\mathrm{MPa}]$ & 190 \\
\hline Failure mode & tension \\
\hline E-modules $[\mathrm{GPa}]$ & 13 \\
\hline Poison ratio & 0.3 \\
\hline
\end{tabular}

Based on these tests, a conservative (lower) design value is derived for the preliminary design of the panel; the stiffness result has been used as reported. In further testing, both this preliminary stiffness and the assumed allowable strength need to be confirmed and updated as the process and product development progresses.

\subsection{Manufacturing}

The shredded C/PPS and PPS granulates were dried in a convection oven for a minimum of $2 \mathrm{~h}$ at $120^{\circ} \mathrm{C}$. Material was weighed and fed to a low-shear piston blender [3,4]. In this machine, the flakes are heated and mixed to a charge, while retaining long fiber length and thereby sustain high mechanical properties. The resulting charge was ejected by a piston, directly transferred to the mold cavity and compression molded. The mold was kept at an isothermal temperature in a 200 tons press. After molding, the to-be-flying access panels were inspected, tested on component level, deburred and primed in the production facilities of GKN Fokker.

\subsection{Mechanical Testing}

Mechanical testing has been performed at Detail and Component Level. Limited Coupon Testing, in the form of 4-point bending, was executed before. [4] Additional plain tensile \& compression is in progress.

\subsubsection{Detail Test}

A dedicated test fixture, illustrated in Figure 5, was designed to test the critical design detail: bending of the laminate edge around the fastener. Although the load is introduced at a point instead of a distributed pressure, the local loading situation is similar. Six specimens were cut from a flat panel using a diamond saw and then sanded to clear the edges. All tests were conducted at room temperature. The load was introduced by a $5 \mathrm{~mm}$ radius fixture at a crosshead speed of $2 \mathrm{~mm} / \mathrm{s}$ in a universal testing machine (see Figure 5). 


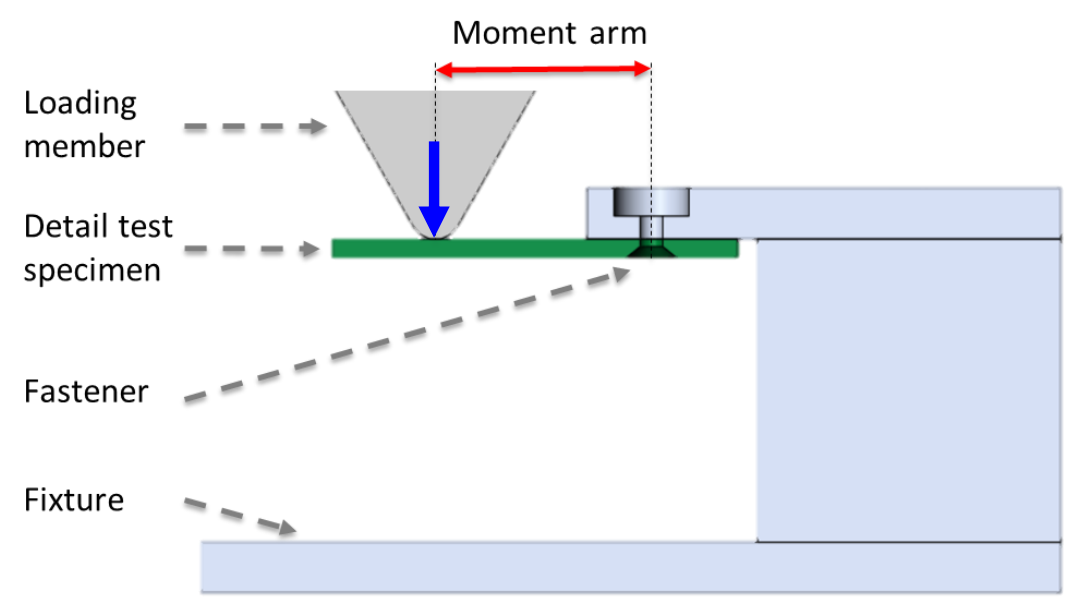

Figure 5. Detail test setup

\subsubsection{Component test}

For this novel and unqualified technology, it was planned that final proof of strength was to be demonstrated by testing a representative panel up to failure or $300 \%$ of LL, whatever was to occur first. The load level of $300 \%$ of the design load is above UL and was selected to not only cover the usual safety factor, but also to address environment knockdowns (by temperature, moisture) and scatter.

Goals of the test were to proof sufficient strength at UL and to verify if the aerodynamic deformation requirement at LL was met. Moreover the failure mode(s), if any, were to be investigated. In order to do so, a test set-up was created which is representative for both the support from the surrounding rotorcraft structure as well as the aerodynamic loads sustained in flight: the panel was to be supported along its edges and subjected to a controlled (under)pressure; deformation was to be measured in the center of the panel. During the test, the panels' critical stiffeners are loaded in tension (the critical failure mode from coupon tests). The test set-up is schematized in Figure 6.

Since both the low-shear mixing process as well as the proposed inspection methods were new and unqualified, the access panels intended for actual flight were to subjected to a proof load of $100 \%$ LL using the same test set-up. 


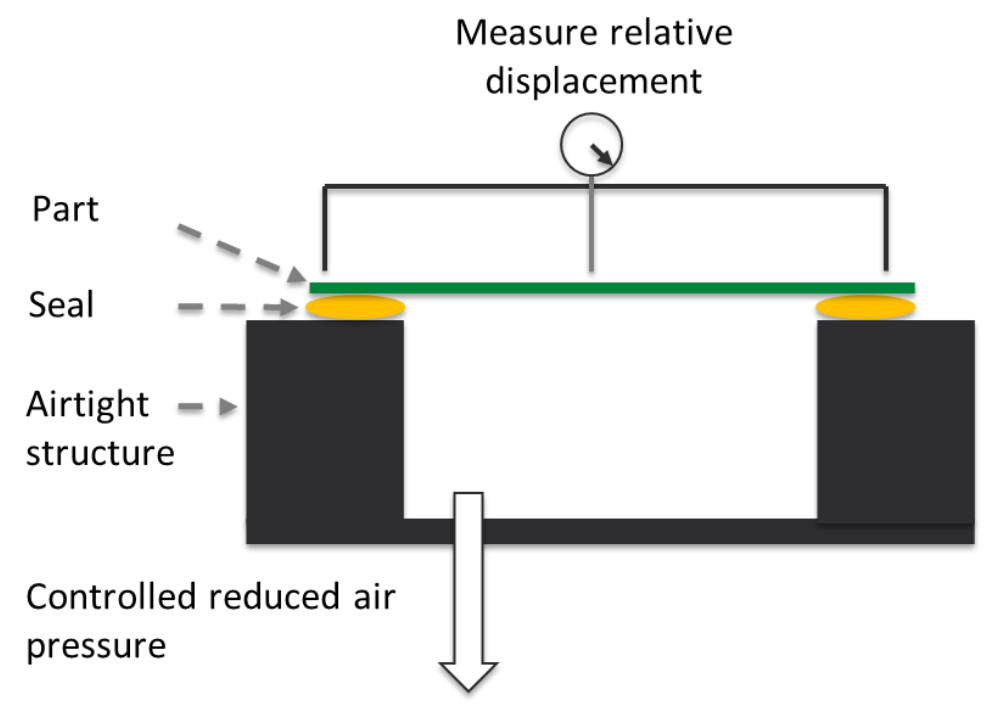

Figure 6. Schematic test set-up for Component Test

\section{RESULTS AND DISCUSSION}

\subsection{Manufacturing}

Several access panels were manufactured by a preliminary process specification, see Figure 7. The production times were below 30 minutes per panel. The part is net-shaped and thus flash could be easily removed without NC trimming. This batch process and the use of a prototype low-shear mixer result in a part weight coefficient of variation $(\mathrm{CoV})$ below $5 \%$. Warpage and small deviation of geometric accuracy were observed and could partly be resolved by relaxation at elevated temperature. All these items can be improved by further industrial development of the process and automation, but the recycling solution already shows a major cycle time and cost reduction compared to current production technologies like hand-layup, the production method of the current access panel. The proposed solution is especially cost-effective since there is limited labor involved and no need for an autoclave or trimming step. An additional benefit is the weight reduction of $9 \%$ compared to the currently applied access panels made of carbon fiber reinforced epoxy material by hand lay-up. 


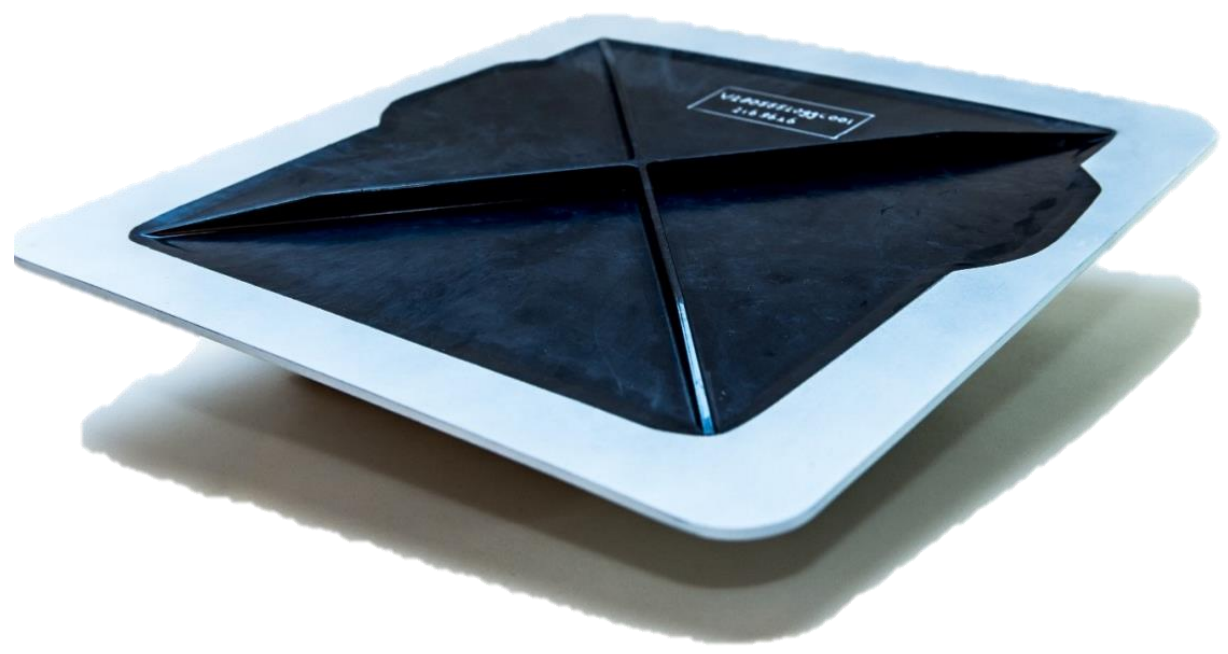

Figure 7. Developed demonstrator access panel for the rotorcraft

\subsection{Mechanical Testing}

\subsubsection{Detail test}

All specimens showed consistent tensile failure at the fastener hole, as predicted. The (gross) stress in the specimen at the location of the fastener is calculated considering the classic formula for determining the bending stress in a beam under simple bending. The cross sectional area reduction of the fastener hole and stress concentrations phenomena are not included. The conservative average estimated stress at failure is $202 \mathrm{MPa}$ with a $\mathrm{CoV}$ of $16 \%$. These gross values are roughly a factor 2 higher than the local maximum peak stresses at UL, shown by the FEM study and correspond well with flexural strength data from previous studies. The data obtained in this study give large confidence regarding the structural integrity near the fastener.

\subsubsection{Component test}

Three representative panels were selected from the produced batch. From these panels, the 'least perfect' upon visual inspection was selected for the failure test. Air pressure under the panel was reduced in steps to $100 \%$ of LL and the deformation was measured. During subsequent load increases, audial observations (slight cracking noises) were made between 150\% and 290\% LL. Nevertheless, 300\% LL was reached successfully and after 3 seconds, the load was removed. Figure 8 depicts the test in execution. 


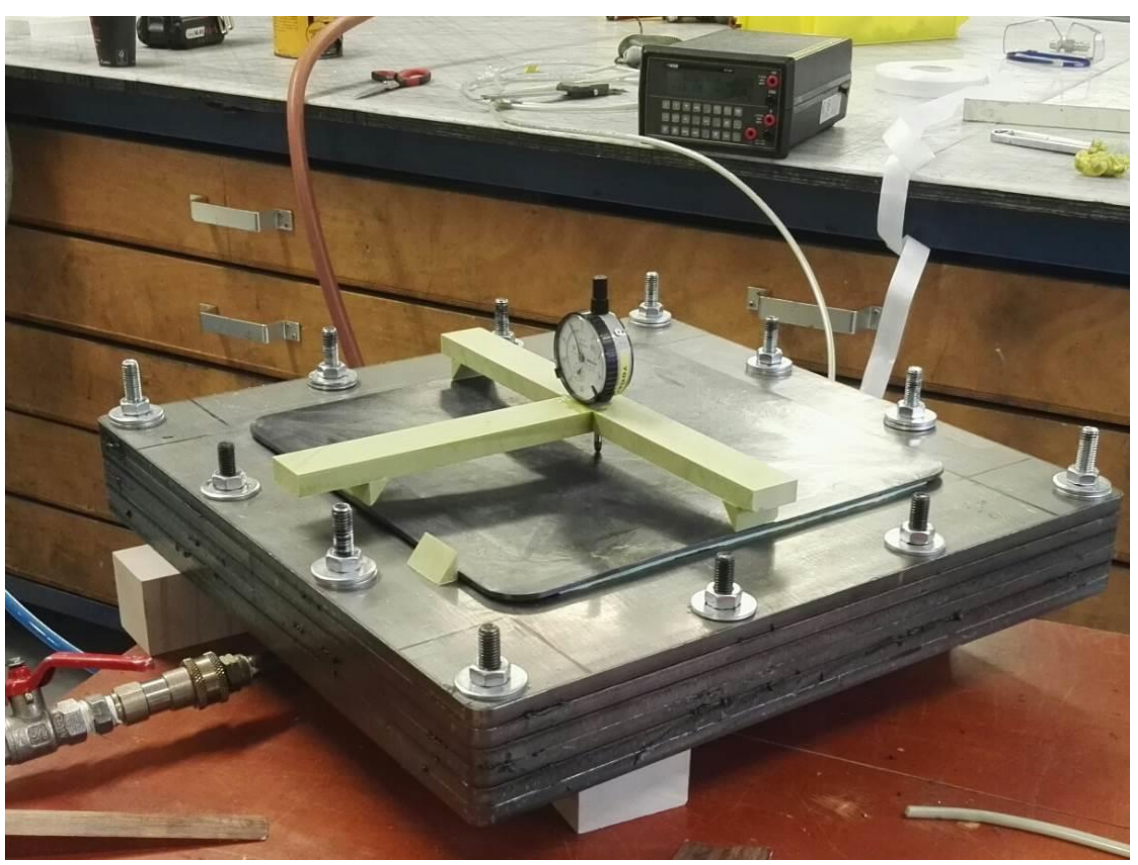

Figure 8. Component test in execution

After removal of the tested panel, a detailed visual inspection was conducted at the stiffener. Two small initial failures were detected at the expected locations: very small cracks originating from manufacturing imperfections at the surface near the stiffener crossing. Progression of the cracks stopped roughly halfway in the stringer, see Figure 9 for their location. As a result, the panel was able to sustain any further loading without subsequently failure. Moreover, the deformation at LL was within requirement and in line with FEM predictions. Therefore: test successfully passed.

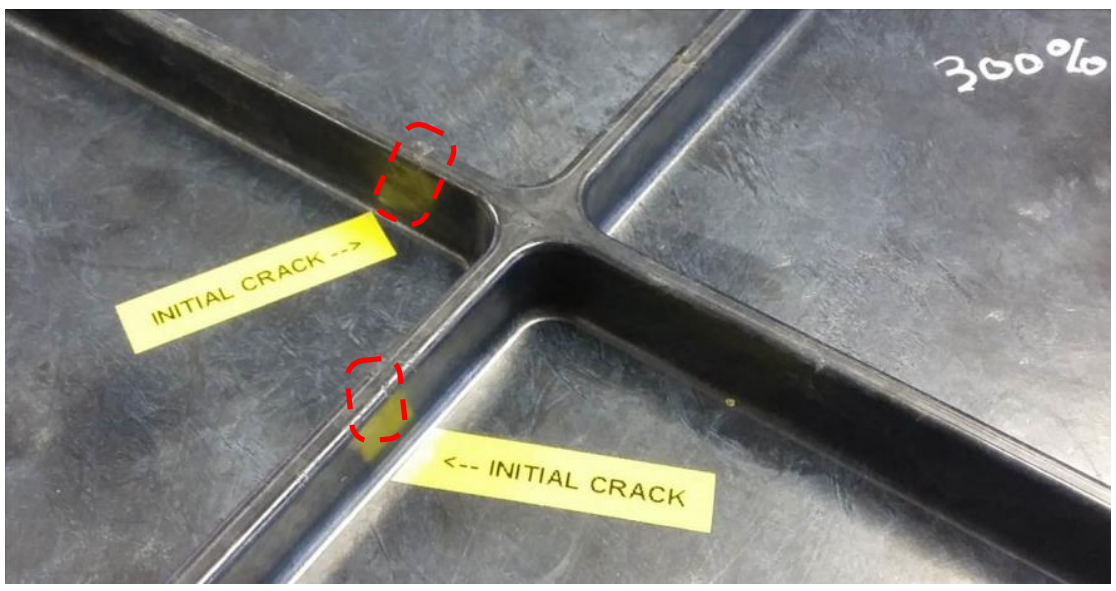

Figure 9. Post-test inspection result (300\% LL test), red circles indicate initial cracks

After the 300\% LL test and inspection, the other two panels were proof-loaded to 100\% LL. No observations were made during the test (no noises) and the post-test inspection did not reveal any defect or crack. Moreover, the stiffness of these panels was found to be according specifications, 
with the deflection at the center within a $10 \%$ margin w.r.t. the requirement. Therefore these two panels were approved for flight.

\subsection{Further development}

The developed application and its process demonstrates that similar solutions are feasible for high-end products. Thanks to the short cycle time, this process is also suitable for markets with larger volumes than aerospace. Currently, several actions are performed to evaluate the production process for serial production. Additional testing (especially coupon testing) and further industrialization efforts (repetitiveness, geometrical stability) are foreseen necessary to qualify the process. Further attention is given to geometric accuracy. More detailed cost and environmental studies are being researched; quality control and inspection is also examined.

At the same time, a feasibility study is executed to see if the applied approach and recycling route can be applied in other aerospace applications, such as (non-structural) fairings, covers \& system brackets. The results regarding cost and weight reduction look very promising for several types of parts.

\section{CONCLUSIONS}

The developed TPC recycling solution offers the possibility to retain long fibers and therefore high mechanical properties at short cycle times. The feasibility of this cradle-to-cradle solution will be further proven by a flying prototype of an access panel for a rotorcraft. This panel has been designed against fully representative set of requirements, manufactured and successfully tested. TPC waste material of other components for the same rotorcraft have been recycled in the production of these access panels.

Desired complex features have demonstrated to be possible and offer the opportunity for stiffeners, which not only increase the geometric stiffness, but also enable to distribute stress more homogenously. In comparison to the current carbon/epoxy hand lay-up solution, the resulting product is $9 \%$ lighter, significantly more cost-effective and made of recycled material (fiber and matrix). Flight test demonstration with the recycled thermoplastic parts installed on the rotorcraft is scheduled for 2019.

\section{ACKNOWLEDGEMENTS}

This project was financed by the Dutch Organization of Applied Research - SIA, through the project grant SIA-RAAK 2014-01-72PRO. The authors are grateful to the TPC-Cycle project partners: TenCate Advanced Composites (Toray Group), GKN Fokker, Cato Composite Innovations, Dutch Thermoplastic Components and Nido Recycling Techniek. The work of Kevin Donderwinkel on the conceptual design is gratefully acknowledged.

\section{REFERENCES}

[1] Offringa, Arnt R. "Thermoplastic applications composites-rapid". Compos Part A 27 (1996): 329- 336. https://doi.org/10.1016/1359-835X(95)00048-7

[2] European parliament and the Council of European Union. Directive 200435 EC on Environmental Liability. 2004. 
[3] De Bruijn, T.A., Vincent, G.A. and Van Hattum, F.W.J. "Recycling of long fibre thermoplastic composites by low shear mixing." SAMPE Europe Conference Proceedings. Liege, Belgium, September 13-15, 2016. Society for the Advancement of Material and Process Engineering. pp. 540-546.

[4] De Bruijn T.A., Vincent, G.A. and Van Hattum F.W.J. "Recycling C / PPS laminates into long fibre thermoplastic composites by low shear mixing." Proceedings 21th Internatinoal Conf. Compos. Mater. ICCM21. Xi'an, China, August 20-25, 2017.

[5] AZDEL Inc. Thermoplastic Composites. Azdel Thermoplastic composites design and processing handbook, 1993.

[6] Vincent, G.A., De Bruijn, T.A., Abdul Rasheed, M.I., Wijskamp, S. and Akkerman, R. "Fibre length distributions of shredded thermoplastic composite scrap." Proceedings 21th Internatinoal Conf. Compos. Mater. ICCM21. Xi'an, China, August 20-25, 2017.

[7] Abdul Rasheed, M.I. "Compression molding of chopped woven thermoplastic composite flakes: a study on processing and performance." Ph.D. dissertation, University of Twente, Enschede, The Netherlands, 2016. https://doi.org/10.3990/1.9789036541510

[8] Janney, M., Leroy Newell, W., Geiger, E., Baitcher, N. and Gunder, T. "Manufacturing complex geometry composites with recycled carbon fiber. Proceedings of 54th International SAMPE Symp. Exhib. Baltimore, MD: May 18-21 2009. Society for the Advancement of Material and Process Engineering. pp. 172-184.

[9] Thomason J.L. "The influence of fibre length and concentration on the properties of glass fibre reinforced polypropylene: 5. Injection moulded long and short fibre PP." Compos Part A Appl Sci Manuf. 33 (2002): 1641- 1652. https://doi.org/10.1016/S1359835X(02)00179-3

[10] Vaidya, U., Willis, B., Brahma, S., Wang, Q. and Pillay, S. Processing M, et al. Comparison of wet laid to other discontinuous processed carbon fiber thermoplastic composites. CAMX Conf. Proc. Orlando, Florida, October 13-16, 2014. CAMX - The Composites and Advanced Materials Expo.

[11] US Department of Transportation Federal Aviation Administration Advisory Circular AC20-107B. Composite Aircraft Structure. 2009. 